\title{
Influence of ionic strength and substratum hydrophobicity on the co-adhesion of oral microbial pairs
}

\author{
Rolf Bos, Henny C. van der Mei and Henk J. Busscher \\ Author for correspondence: Henk J. Busscher. Tel: +31503633140 . Fax: +31503633159. \\ e-mail: R.Bos@i med.rug.nl
}

Laboratory for Materia Technica, University of Groningen, Bloemsingel 10, 9712 KZ Groningen, The Netherlands

\begin{abstract}
Co-adhesion between oral microbial pairs (i.e. adhesion of a planktonic microorganism to a sessile organism adhering to a substratum surface) has been described as a highly specific interaction, mediated by stereochemical groups on the interacting microbial cell surfaces, and also as a non-specific, critical colloid-chemical interaction. In a colloid-chemical approach, microbial coadhesion is considered as an interplay between, amongst others, hydrophobic and electrostatic interactions. The aim of this paper was to determine the influence of ionic strength on the co-adhesion of Streptococcus oralis $\mathbf{3 4}$ to either Actinomyces naes/undii T14V-J1 or its mutant strain 5951 adhering to glass in a parallel-plate flow chamber. To this end, the ionic strength of the suspension was varied by the addition of $\mathrm{KCl}$. Another aim was to investigate whether substratum hydrophobicity affected the co-adhesion between the organisms by allowing the sessile organisms (in this case the actinomyces) to adhere either to hydrophilic or to hydrophobic, dimethyldichlorosilane (DDS)coated glass. The kinetics of co-adhesion of S. oralis 34 to the actinomyces decreased with increasing ionic strength, expressed as the ratio, $\chi$, between the local and non-local initial deposition rates of the streptococci in the vicinity of, or far away from, the adhering actinomyces, respectively. In a stationary end-point of co-adhesion, ionic strength appeared not to be a determinant factor for the co-adhesion of S. oralis 34 with A. naeslundii 5951, either when the actinomyces were adhering to hydrophilic glass or to hydrophobic, DDScoated glass. However, for $S$. oralis $\mathbf{3 4}$ co-adhering in a stationary end-point with $A$. naes/undii T14V-J1 in the high-ionic-strength $(250 \mathrm{mM} \mathrm{KCl})$ suspension, co-adhesion was far less on hydrophobic, DDS-coated glass than on hydrophilic glass. It is possible that the hydrophobic fibrils on A. naeslundii T14V-J1 bearing the lectin responsible for co-adhesion were immobilized in the latter case by adsorption to the hydrophobic substratum, making them less available for interaction with the streptococci.
\end{abstract}

Keywords: coaggregation, co-adhesion, hydrophobicity, zeta potentials, ionic strength

\section{INTRODUCTION}

Interactions between micro-organisms and a substratum surface as well as interactions between micro-organisms are important events during the initial stages of biofilm formation and determine the microbial composition and structure of the biofilm in later stages. Physico-chemical properties of the interacting cell and substratum surfaces influence the adhesion of micro-organisms and may

Abbreviation: DDS, dimethyldichlorositane. consequently contribute to species variability in a biofilm (Verrier et al., 1987; Pratt-Terpstra et al., 1989). In addition to cell-substratum interactions, species variability is promoted by micro-organisms that adhere initially, since these organisms may stimulate adhesion of planktonic organisms, a phenomenon known as coadhesion. When interspecies binding occurs, a complex multispecies biofilm, as frequently observed in the oral cavity, will emerge (Gibbons \& Nygaard, 1970).

A physico-chemical approach will most likely never be able to fully explain all aspects of microbial adhesion to 
surfaces, including interspecies binding. Even when adhesion to inert surfaces is considered, the influences of microbial cell-surface appendages (Handley et al., 1991), of highly specific, sparsely distributed receptor sites (Busscher et al., 1992) or of biosurfactant release (Rosenberg, 1986) by adhering organisms will be difficult to incorporate. Consequently, microbial adhesion to substratum surfaces must be considered a multifactorial process, unlikely to be ever explained on the basis of one single mechanism or approach. Considering now the complexity of microbial cell surfaces, it is even more unlikely that a single approach or mechanism can be identified which covers all aspects of microbial coaggregation and co-adhesion.

Often interspecies binding is mediated by lectin or lectinlike carbohydrate interactions (Kolenbrander, 1989). The fundamental forces in lectin-carbohydrate interactions are Lifshitz--van der Waals' forces, electrostatic interactions and hydrogen bonding. Stereospecificity is achieved mainly through the highly directional hydrogen bonds (Quiocho, 1986). Although these short-range interactions (separation distances $<5 \mathrm{~nm}$ ) are of key importance to obtain specificity, the overail surface characteristics of the interacting micro-organisms are equally important. Often, micro-organisms are unable to approach each other close enough, due to, for instance, electrostatic repulsion (separation distances $10-20 \mathrm{~nm}$ ), for stereochemical combinations between highly localized molecular groups to occur. Therefore, in order to adequately describe interspecies binding, overall, longrange and non-directional interaction forces between organisms must also be taken into consideration. Recently, we showed that lectin-mediated interspecies binding between Streptococcus oralis 34 and Actinomyces naesinndii T14V-J1 or its mutant strain 5951 could be described in colloid-chemical terms as a critical balance between attractive Lifshitz-van der Waals' forces and localized electrostatic attraction on the one hand and overall electrostatic repulsion on the other (Bos et al., 1996).

Study of such a delicate force balance requires an experimental system in which other forces such as hydrodynamic shear can be well controlled. With the aid of a parallel-plate flow chamber (Sjollema et al., 1989) equipped with in situ observation and image analysis facilities, it is possible to study the kinetics as well as the spatial arrangement of microbial adhesion under controlled hydrodynamic conditions. Quantification of coadhesion in a parallel-plate flow chamber can be done by monitoring the deposition of one microbial strain (e.g. a streptococcal strain) in the vicinity of an already-adhering but different strain (e.g. actinomyces), while distinguishing between the strains on the basis of their times of arrival at the substratum surface. When, for instance, this methodology was employed to study the role of calcium ions in the co-adhesion between $S$. oralis 34 and $A$. naeslundii 5951, we observed that in buffer with added calcium ions the local initial deposition rate near preadhering actinomyces was maximal and only limited by mass transport. In buffer supplemented with magnesium or barium, however, the local initial deposition rate was 10-fold lower (Bos et al., 1996) than in buffer with calcium added, whereas the non-local initial deposition rate, i.e. streptococcal deposition to the bare substratum, was not influenced by the type of cation added.

Several investigators have shown that substratum hydrophobicity, charge and the ionic strength of the microbial suspension have a pronounced effect on the adhesion of micro-orgarisms, but their effect on co-adhesion is unknown. Therefore, it is the aim of this paper to study the influence of ionic strength and substratum hydrophobicity on co-adhesion of two pairs of coaggregating oral microbial strains. To this end, co-adhesion experiments were carried out in a parallel-plate flow chamber, using hydrophilic glass and silanized hydrophobic glass as substrata. The ionic strength of the suspension was varied by the addition of $\mathrm{KCl}$.

\section{METHODS}

Bacterial strains, culture conditions and harvesting. Two pairs of coaggregating streptococci and actinomyces were used which showed exclusively lectin-mediated coaggregation: Streptococcus oralis 34 (formerly called S. sanguis 34) with either Actinomyces naeslundii $\mathrm{T} 14 \mathrm{~V}-\mathrm{J} 1$ or 5951 . A. naeslundii $\mathrm{T} 14 \mathrm{~V}-\mathrm{J} 1$ bears two types of fibrils, mediating the interaction with salivary proteins (type 1 fibrils) and lectin-like fibrils (type 2 fibrils), responsible for the interaction with sugars; $A$. naeslundii 5951 only possesses type 2 fibrils (Cisar et al., 1988). All strains were cultured in Schaedler's broth supplemented with $0.01 \mathrm{~g}$ haemin $1^{-1} ; S$. oralis 34 was incubated in ambient air while the actinomyces were incubated in an anaerobic cabinet (DW Scientific) in an atmosphere of $\mathrm{H}_{2} / \mathrm{N}_{2} / \mathrm{CO}_{2}(10: 85: 5$, by vol.) at $37^{\circ} \mathrm{C}$ (strains were kindly provided by Dr P. E. Kolenbrander and Dr J. O. Cisar, NIH, Bethesda, USA). For each experiment, strains were inoculated from blood agar in a batch culture. This culture was used to inoculate a second culture which was grown for $16 \mathrm{~h}$ prior to harvesting.

Bacteria were harvested by centrifugation $(5 \mathrm{~min}$ at $10000 \mathrm{~g}$ ), washed twice with demineralized water and resuspended in the appropriate buffer. To break bacterial chains and aggregates, cells were sonicated for $30 \mathrm{~s}$ at $30 \mathrm{~W}$ (Vibra Cell model 375; Sonics and Materials). Sonication was done intermittently while cooling in an ice/water-bath. These conditions were found not to cause cell lysis in any strain, nor did the supernatant of pelleted sonicated cells cause coaggregation of the partner cells.

Actinomyces were suspended in buffer $(2 \mathrm{mM}$ potassium phosphate, $50 \mathrm{mM}$ potassium chloride and $0.5 \mathrm{mM}$ calcium chloride, $\mathrm{pH} 6 \cdot 8$ ) to a density of $1 \times 10^{8} \mathrm{ml}^{-1}$. Streptococci were suspended in buffer, with the appropriate amount of $\mathrm{KCl}$ added, to a density of $3 \times 10^{8} \mathrm{ml}^{-1}$.

Substrata. Glass plates $(7.5 \times 5 \mathrm{~cm})$, constituting top and bottom plates of the parallel-plate flow chamber, were used as substrata and were cleaned as described previously by Sjollema et al. (1989), yielding a $0^{\circ}$ water contact angle. Hydrophobic substrata were obtained by silanization [dimethyldichlorosiloxane (DDS)] of clean glass plates as previously described by Ruardy et al. (1995), yielding a hydrophobic surface with a water contact angle of $92^{\circ}$.

Microelectrophoresis. Electrophoretic mobilities of the bacteria in the appropriate buffers were measured with a Lazer Zee Meter 501 (PenKem), which uses scattering of incident laser light to enable detection of the bacteria at relatively low magnifications. Aliquots of the bacterial suspensions were added 


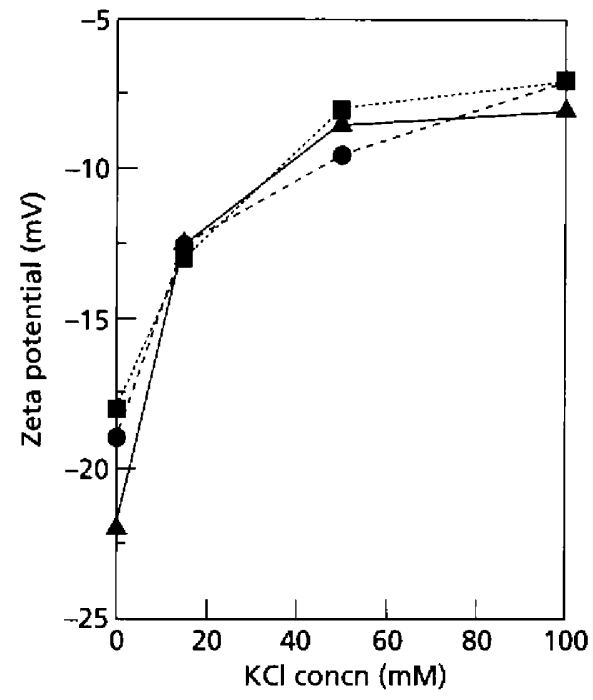

Fig. 1. Zeta potentials of $S$. oralis $34(-\mathbf{A} \longrightarrow$ ) and $A$. naeslundii T14V-J1 (-- -) and 5951 (... ....), in a $2 \mathrm{mM}$ potassium phosphate buffer with $0.5 \mathrm{mM} \mathrm{CaCl}$ added, as a function of ionic strength, i.e. the amount of $\mathrm{KCl}$ added. Experiments were done in duplicate with separate cultures, yielding standard deviations of $1.5 \mathrm{mV}$ over six readings of the zeta potential, which equals the variation between two cultures.

to a density of approximately $1 \times 10^{8} \mathrm{ml}^{-1}$ to buffer with various amounts of added $\mathrm{KCl}$. The voltage difference across the electrophoresis chamber was set to $150 \mathrm{~V}$ and the electrophoretic mobilities measured were converted to apparent zeta potentials through the use of the Smoluchowski equation (Hiemenz, 1977). All zeta potentials reported are the mean values of measurements on two different cultures.

Streaming potential. Streaming potentials of the substratum surfaces were measured in the appropriate buffers employing rectangular platinum electrodes $(5.0 \times 25.0 \mathrm{~mm})$ located at both ends of a parallel-plate flow chamber (Van Wagenen \& Andrade, 1980). Two glass slides separated by a $0.2 \mathrm{~mm}$ Teflon gasket constituted the top and bottom plates of the chamber. Streaming potentials were measured at ten different pressures ranging from 37.5 to 150 Torr $(5-20 \mathrm{kPa})$ and each pressure was applied for $10 \mathrm{~s}$ in both directions. Subsequently, zeta potentials were derived from the pressure dependence of the streaming potentials, neglecting surface conductivity.

Parallel-plate flow chamber system and image analysis. The parallel-plate flow chamber and image analysis procedures employed have been described in detail previously (Sjollema $e t$ al., 1989; Bos et al., 1994), but will be briefly repeated for completeness. Microbial adhesion was observed in situ on the bottom plate of the parallel-plate flow chamber $(7.5 \times 3.8 \mathrm{~cm})$ with a channel height of $0.06 \mathrm{~cm}$. Observations were done with a CCD-MXR camera (High Technology), mounted on a phasecontrast microscope (Olympus $\mathrm{BH}-2$ ) equipped with a $\times 40$ ultra-long working distance objective (Olympus LLWD-CD Plan $40 \mathrm{PL}$ ). The camera was connected to an image analyser (TEA; Difa).

Live images were Laplace-filtered after subtraction of an out-offocus image. Thereafter, adhering bacteria were discriminated from the background by single-grey-value thresholding. This yielded binary black-and-white images which were subsequently stored on disk. In the setup, an image covers a surface area of $0.016 \mathrm{~mm}^{2}$.

Deposition protocol. Co-adhesion experiments were cartied out at $22^{\circ} \mathrm{C}$. Microbial suspensions were circulated through the system by means of hydrostatic pressure at a wall shear rate of $10 \mathrm{~s}^{-1}$, which yields a laminar How with a Reynolds number of $0 \cdot 6$.

The actinomyces suspension was circulated first through the system until a surface density of $1.0 \times 10^{6} \mathrm{~cm}^{-2}$ was reached. Thereafter, the flow was switched to buffer with an appropriate concentration of $\mathrm{KCl}$ to remove all unattached actinomyces from the flow chamber and the tubes. The co-adhesion phase started when the flow was switched to the streptococcal suspension and image acquisition was set in progress for $4 \mathrm{~h}$.

Data analysis. Data analysis was done as previously described (Sjollema \& Busscher, 1990; Bos et al., 1995), distinguishing adhering streptococci from actinomyces on the basis of their times of arrival. Co-adhesion was quantified by determining the number of streptococci adhering in a shell around the centre of the pre-adhering actinomyces and to other parts of the substratum. Based on this analysis, the total initial deposition rate, $j_{0}$, i.e. the number of organisms initially adhering per unit time and area, can be written as

$j_{0}=\phi j_{0,1}+(1-\phi) j_{0 . \mathrm{nl}}$

in which $j_{0,1}$ and $j_{0, n 1}$ represent the initial deposition rate within the shells immediately around pre-adhering actinomyces ('local initial deposition rate') and the initial deposition rate outside these shells on the bare substratum ("non-local initial deposition rate'), respectively. $\phi$ is the fraction of the substratum surface contained within the shells around the pre-adhering actinomyces. For the present experiments, the radius of the shells was chosen to be $1 \cdot 1 \mu \mathrm{m}$ and $\phi$ can be calculated to be $0 \cdot 07$ based on the density and the dimensions of the pre-adhering actinomyces. For a co-adhering pair, the ratio between local and non-local initial deposition rate, $\chi$, can become up to 19 times unity, whereas for a non co-adhering pair $\chi$ is equal or smaller than unity (Bos et al., 1995).

Co-adhesion in a stationary end-point was quantified by means of radial pair distribution functions, revealing the relative prevalence of streptococci adhering in the immediate vicinity of the pre-adhering actinomyces as compared to the mean density of adhering streptococci. The term 'stationary end-point' was chosen to denote the end-point of the co-adhesion process rather than to use the term 'equilibrium co-adhesion', because the use of the word 'equilibrium' implies reversibility, which has not been established in microbial co-adhesion. Also in this respect, the expression 'stationary state of co-adhesion' was considered inappropriate to use since it might cause confusion with the expressions used to designate microbial growth states. Local densities of adhering streptococci were determined in shells with thickness $d r(0 \cdot 16 \mu \mathrm{m})$ at distances $r$ from the centre of the pre-adhering actinomyces. This procedure was performed for each adhering actinomyces. The local density of streptococci around pre-adhering actinomyces was normalized with respect to the mean density of the streptococci, yielding the distribution function $g_{21}(r)$. When streptococci are randomiy distributed over the entire substratum surface, $g_{21}(r)$ equals unity. However, if there is preferential adhesion around actinomyces, then $g_{21}(r)>1$. Such regions must of course be compensated for by regions where $g_{21}(r)<1$.

Details about the exact calculations of the tadial pair distribution function have been given elsewhere (Sjollema \& Busscher, $1990)$. 


\section{RESULTS}

Fig. 1 presents the zeta potentials of the strains used as a function of the $\mathrm{KCl}$ concentration. All strains clearly displayed less negative zeta potentials with increasing ionic strength.

The zeta potentials of the hydrophilic and hydrophobic, DDS-coated glass were similar in the low (15 and $50 \mathrm{mM} \mathrm{KCl}$-ionic-strength buffers and amounted to $-23 \mathrm{mV}$ on average. In the $250 \mathrm{mM} \mathrm{KCl}$ buffer, however, the hydrophilic glass became less negative $(-14 \mathrm{mV})$, while the zeta potential of the hydrophobic, DDS-coated glass remained constant $(-23 \mathrm{mV})$.

Fig. 2 presents examples of the deposition kinetics of streptococci from a low- and a high-ionic-strength buffer to hydrophilic glass with pre-adhered A. naeslundii 5951.

A quantitative analysis of streptococcal deposition far away from pre-adhering actinomyces ("non-local' data) is given in Table 1, showing that the non-local initial deposition rates of $S$. oralis 34 as well as the non-locally adhering numbers of micro-organisms after $4 \mathrm{~h}$ varied both with ionic strength and with substratum hydrophobicity. The non-local initial deposition rates decrease with increasing ionic strength on the hydrophilic substratum but not on hydrophobic, DDS-coated glass. In the low- and intermediate-ionic-strength suspensions, both non-local initial deposition rates as well as numbers of organisms adhering after $4 \mathrm{~h}$ are lower on a hydrophobic substratum than on a hydrophilic substratum. However, in the high-ionic-strength suspension both the initial deposition rates and the numbers adhering after $4 \mathrm{~h}$ are similar or higher on the hydrophobic substratum.

Tables 2 and 3 summarize the quantitative analysis of local streptococcal deposition in the close vicinity of the preadhering actinomyces, i.e. co-adhesion. With regard to the kinetics of local $S$. oralis 34 deposition, it can be noted from Tabie 2 that, for both microbial pairs, the local initial deposition rates decrease with increasing ionic strength. The influence of substratum hydrophobicity on local initial deposition rates is more pronounced, however, for $S$. oralis 34 co-adhering with $A$. naeslundii $\mathrm{T} 14 \mathrm{~V}-\mathrm{J} 1$ than with 5951. Similar trends can be seen when co-adhesion kinetics are quantified by the ratio, $\chi$, between local and non-local initial deposition rates.

Table 3 summarizes the characteristics of the radial pair distribution functions in a stationary end-point of $\mathrm{co}^{-}$ adhesion. There is no significant effect of either ionic strength or substratum hydrophobicity on the screening distance $r_{\mathrm{s}}$, indicating that streptococci and actinomyces can become ciosely associated. The effects of ionic strength and substratum hydrophobicity are also less upon co-adhesion in a stationary end-point, as judged from the radial distribution function $g_{21}\left(r_{\mathrm{p}}\right)$, than for the kinetics of co-adhesion. Interestingly, co-adhesion in a stationary end-point decreases only with ionic strength for the pair $S$. oralis 34 and $A$. naeslundii $\mathrm{T} 14 \mathrm{~V}-\mathrm{J} 1$ on a hydrophobic substratum, but not on a hydrophilic substratum.

\section{DISCUSSION}

In this paper, we studied the influence of ionic strength of microbial suspensions and substratum hydrophobicity upon the interaction between two micro-organisms, one of which is adhering to a substratum surface. Ionic strength directly determines the range and magnitude of the electrostatic interactions between the microorganisms and consequently the co-adhesion between the microbial pairs studied is influenced by the ionic strength of the microbial suspension. At the onset of this study, we anticipated little effect of substratum hydrophobicity upon co-adhesion, because we felt that substratum hydrophobicity would not be of direct influence on the interaction between two micro-organisms, one of which is adhering to a substratum surface. The observation that co-adhesion between $S$. oralis 34 and $A$. naeslundii $\mathrm{T} 14 \mathrm{~V}$ J1 from the high-ionic-strength buffer in a stationary endpoint occurred on hydrophilic glass, but hardly on hydrophobic, DDS-coated glass was surprising to us.

According to the classical DLVO theory (developed by and named after Derjaguin, Landau, Verwey and Overbeek) for the interaction between micro-organisms and a substratum (Rutter \& Vincent, 1980), increasing ionic strength minimizes both repulsive and attractive electrostatic interaction forces as well as their range. As most natural surfaces, including microbial cell surfaces, are negatively charged, microbial adhesion generally occurs despite electrostatic repulsion between the interacting surfaces. In the classical DLVO theory, it is envisaged that attractive Lifshitz-van der Waals' forces overcome the electrostatic repulsion and mediate microbial adhesion. Although such a simplified approach of microbial adhesion has proven merits (Van Loosdrecht \& Zehnder, 1990), classical DI.VO theory does not include acid-base interactions as accounted for in an extended DLVO approach developed by Van Oss et al. (1986). Possibly, the hydration forces described in the literature (Pashley \& Israelachvili, 1984) as well as 'hydrophobic interactions' (Van Oss, 1995) may be considered as a corollary of these acid-base interactions. These hydration forces are repulsive for hydrophilic interacting surfaces and increase with increasing ionic strength (Pashley \& Israelachvili, 1984). Several studies have implicated a role of hydration forces in the adhesion of inert particles (Elimelech, 1990) and micto-organisms to substratum surfaces (Sjollema et al., 1988).

There are a number of trends in the 'non-local' adhesion data that are in line with the above described (extended) DLVO theory. First, the decrease in non-local initial deposition rates with increasing ionic strength is contrary to expectations on the basis of classical DLVO theory, which predicts an increase in deposition rate through the reduction in electrostatic repulsion. However, this reduction in deposition rate as experimentally observed for high $\mathrm{KCl}$ concentrations is in line with the existence of repulsive hydration forces, as described in the extended DLVO theory and occurring on a hydrophilic substratum. Second, on hydrophobic, DDS-coated glass, the hydration forces are attractive, but are counterbalanced by 


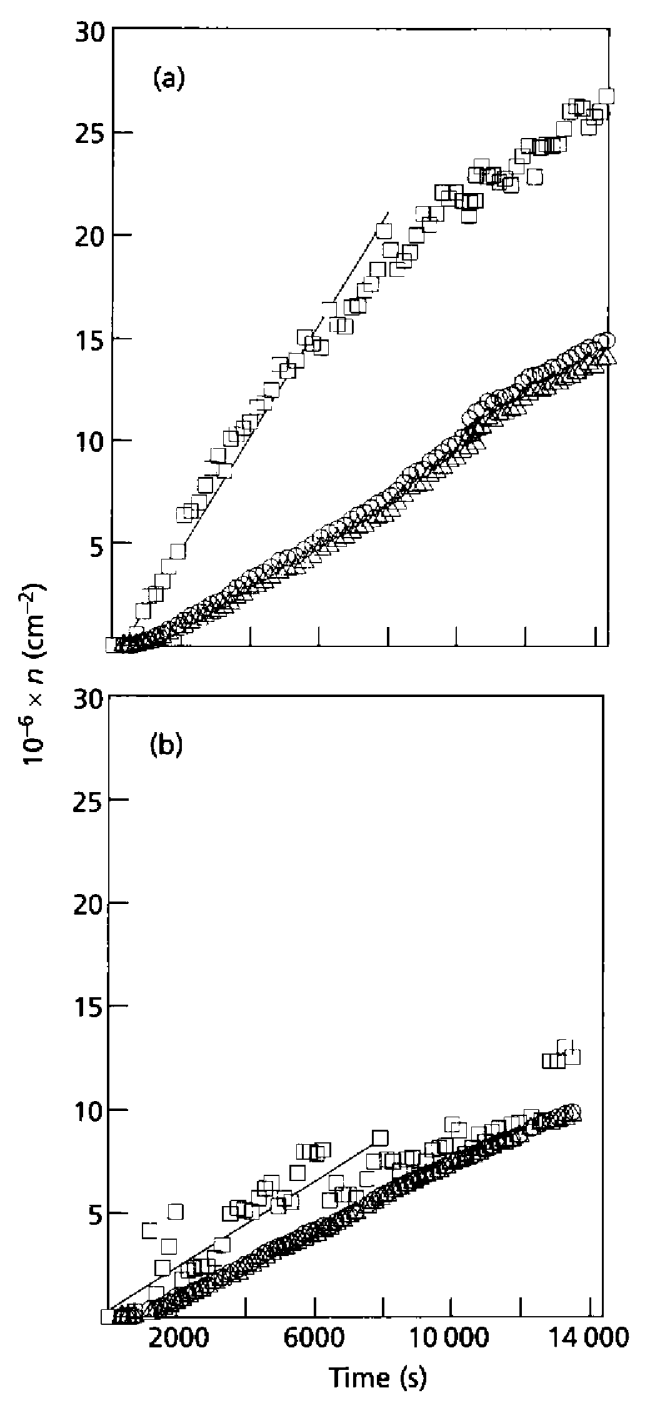

Fig. 2. Examples of the kinetics of co-adhesion of S. oralis 34 deposited from buffer containing $15 \mathrm{mM} \mathrm{KCl}$ (a) or $250 \mathrm{mM} \mathrm{KCl}$ (b) to glass with pre-adhering $A$. naes/undii 5951 locally, in a shell of $1.1 \mu \mathrm{m}$ around the pre-adhering actinomyces $(\square)$, non-locally, for the area outside these shells $(\triangle)$ and for the entire surface $(O)$.

stronger electrostatic repulsion than on hydrophilic glass. The net effect of this interplay may explain why the nonlocal initial deposition rates of streptococci are less influenced by ionic strength on hydrophobic, DDS-coated glass than on hydrophilic glass.

Ellen $e$ al. (1994) studied the lectin-mediated co-adhesion between $A$. naeslundii WVU $398 \mathrm{~A}$ and S. oralis 34 as a function of the $\mathrm{LiCl}$ and $\mathrm{KCl}$ concentration by mixing hexadecane droplets with adhering streptococci and actinomyces, while subsequently allowing the aqueous and hexadecane phases to separate. The turbidity of the aqueous phase was considered as a measure of the coadhesion between the strains, taking appropriate controls into account. Although the influence of $\mathrm{LiCl}$ and $\mathrm{KCl}$ concentration upon co-adhesion was minor, a $20 \%$ reduction in co-adhesion rate was observed for both salts at a concentration of $500 \mathrm{mM}$. In contrast, McIntire et al. (1979) repeatedly mixed microbial pairs on a vortex mixer and demonstrated that $1 \mathrm{M} \mathrm{NaCl}$ did not inhibit the interaction between $A$. naeslundii $\mathrm{T} 14 \mathrm{~V}$ and $S$. oralis 34 (formerly called S. sanguis 34).

Our study revealed a major effect of ionic strength on the kinetics of co-adhesion, whereas the effects of ionic strength on co-adhesion in a stationary end-point appeared to be strain- and substratum-hydrophobicitydependent. Unfortunately, in neither of the above studies by Ellen et al. (1994) or McIntire et al. (1979) was mass transport properly controlled as in the parallel-plate flow chamber and it is virtually impossible to distinguish between kinetic and stationary state effects. Possibly due to the better mass transport control in the present study, we found that the kinetics of co-adhesion are more affected by ionic-strength than in the studies of Ellen et al. (1994) or McIntire et al. (1979), with the local initial deposition rates of the streptococci decreasing with increasing ionic strength. Although this decrease might be explained by the occurrence of repulsive hydration forces between the micro-organisms, an alternative explanation could be based on the suggestion that coadhesion results in part from electrostatic attraction between small, oppositely charged domains on the interacting cell surfaces. The range as well as the magnitude of this electrostatic attraction decrease with increasing ionic strength. Alternatively, it is suggested that potassium adsorption may prevent calcium bridging, as a mechanism contributing to co-adhesion between microbial pairs (Bos et al., 1996).

Local initial deposition rates of $S$. oralis 34 near preadhering $A$. naeslundii on hydrophobic, DDS-coated glass are significantly lower than on hydrophilic glass. The lectins on the actinomyces, which mediate the interaction with carbohydrates on the streptococcal cell surfaces, reside on hydrophobic fibrils, which can be up to $1 \mu \mathrm{m}$ long (Cisar \& Vatter, 1979). Thermodynamically, it is likely that these hydrophobic fibrils become immobilized by adsorption to hydrophobic, DDS-coated glass (Absolom et al., 1983; Busscher et al., 1984), thus making them less available for the interaction with planktonic streptococci and yielding reduced local initial deposition rates. Co-adhesion in a stationary end-point is not affected by ionic strength, except for the pair $S$. oralis 34 and $A$. naeslundii T14V-J1 on hydrophobic, DDScoated glass, which is probably related again to the fact that the fibrils bearing the lectin responsible for coadhesion on $A$. naeslundii $\mathrm{T} 14 \mathrm{~V}-\mathrm{J} 1$ are immobilized by adsorption to hydrophobic, DDS-coated glass.

In summary, the results of this paper demonstrate that the kinetics of co-adhesion of two oral microbial pairs decrease with increasing ionic strength of the microbial suspension, through the influence of repulsive hydration forces or a reduction in localized electrostatic attraction. Substratum hydrophobicity influenced the co-adhesion between $S$. oralis 34 and $A$. naeslundii, possibly due to adsorption of the fibrils present on the actinomyces cell 
Table 1. Non-local initial deposition rates and numbers of adhering S. oralis 34 after $4 \mathrm{~h}$ for hydrophilic and hydrophobic DDS-coated glass with pre-adhering A. naes/undii T14VJ1 or 5951

Experiments were carried out in duplicate with separately cultured bacteria and results varied by less than $20 \%$.

\begin{tabular}{|c|c|c|c|c|c|}
\hline \multirow{2}{*}{$\begin{array}{l}\text { A. naeslundii } \\
\text { strain }\end{array}$} & \multirow{2}{*}{$\begin{array}{c}\mathrm{KCl} \\
\text { conch } \\
(\mathrm{mM})\end{array}$} & \multicolumn{2}{|c|}{ Hydrophilic } & \multicolumn{2}{|c|}{ Hydrophobic } \\
\hline & & $\begin{array}{c}j_{0, \mathrm{nl}} \\
\left(\mathrm{cm}^{-2} \mathrm{~s}^{-1}\right)\end{array}$ & $\begin{array}{c}10^{-6} \times n_{\mathrm{ads}, \mathrm{nl}} \\
\left(\mathrm{cm}^{-2}\right)\end{array}$ & $\begin{array}{c}j_{0, \mathrm{nl}} \\
\left(\mathrm{cm}^{-2} \mathrm{~s}^{-1}\right)\end{array}$ & $\begin{array}{c}10^{-6} \times n_{\mathrm{ads}, \mathrm{nl}} \\
\left(\mathrm{cm}^{-2}\right)\end{array}$ \\
\hline T14V-J1 & 15 & 580 & $10 \cdot 4$ & 306 & $5 \cdot 8$ \\
\hline T14V-J1 & 50 & 974 & $13 \cdot 8$ & 686 & $9 \cdot 6$ \\
\hline $\mathrm{T} 14 \mathrm{~V}-\mathrm{J} 1$ & 250 & 278 & $3 \cdot 8$ & 380 & $7 \cdot 4$ \\
\hline 5951 & 15 & 606 & $12 \cdot 1$ & 490 & $9 \cdot 2$ \\
\hline 5951 & 50 & 854 & $10 \cdot 1$ & 712 & $9 \cdot 8$ \\
\hline 5951 & 250 & 437 & 6.7 & 724 & 6.4 \\
\hline
\end{tabular}

Table 2. Kinetics of co-adhesion expressed as local initial deposition rates and as ratios, $\chi$, between local and non-local initial deposition rates of 5 . oralis 34 to hydrophilic and hydrophobic (DDS-coated) glass with pre-adhering $A$. naes/undii T14V-J1 or 5951

Experiments were carried out in duplicate with separately cultured bacteria and results varied by less than $20 \%$

\begin{tabular}{|c|c|c|c|c|c|}
\hline \multirow{2}{*}{$\begin{array}{l}\text { A. naeslundii } \\
\text { strain }\end{array}$} & \multirow{2}{*}{$\begin{array}{c}\mathrm{KCl} \\
\text { concn } \\
(\mathrm{mM})\end{array}$} & \multicolumn{2}{|c|}{ Hydrophilic } & \multicolumn{2}{|c|}{ Hydrophobic } \\
\hline & & $\begin{array}{c}j_{0,1} \\
\left(\mathrm{~cm}^{-2} \mathrm{~s}^{-1}\right)\end{array}$ & $\chi$ & $\begin{array}{c}j_{0,1} \\
\left(\mathrm{~cm}^{-2} \mathrm{~s}^{-1}\right)\end{array}$ & $x$ \\
\hline T14V-J1 & 15 & 2880 & $5 \cdot 0$ & 1704 & $5 \cdot 6$ \\
\hline T14V-J1 & 50 & 3522 & $3 \cdot 6$ & 1481 & $3 \cdot 1$ \\
\hline T14V-J1 & 250 & 1532 & $4 \cdot 3$ & 726 & 1.9 \\
\hline 5951 & 15 & 3114 & $5 \cdot 1$ & 2605 & $5 \cdot 3$ \\
\hline 5951 & 50 & 4280 & $5 \cdot 0$ & 2267 & $3 \cdot 2$ \\
\hline 5951 & 250 & 1000 & $2 \cdot 3$ & 1064 & $1 \cdot 5$ \\
\hline
\end{tabular}

Table 3. Characteristic features of the radial pair distribution functions for the coadhesion of $S$. oralis 34 with $A$. naes/undii T14V-J1 and 5951 pre-adhering to hydrophilic or hydrophobic (DDS-coated) glass, including the screening distances, $r_{5}$, and the radial distribution function at the distance of preferential co-adhesion, $g_{21}\left(r_{\mathrm{p}}\right)$

Experiments were carried out in duplicate with separately cultured bacteria and results varied by less than $20 \%$.

\begin{tabular}{|c|c|c|c|c|c|}
\hline \multirow{2}{*}{$\begin{array}{l}\text { A. naeslundii } \\
\text { strain }\end{array}$} & \multirow{2}{*}{$\begin{array}{c}\mathrm{KCl} \\
\text { concn } \\
(\mathrm{mM})\end{array}$} & \multicolumn{2}{|c|}{ Hydrophilic } & \multicolumn{2}{|c|}{ Hydrophobic } \\
\hline & & $r_{s}(\mu \mathrm{m})$ & $g_{21}\left(r_{\mathrm{p}}\right)$ & $r_{\mathrm{s}}(\mu \mathrm{m})$ & $g_{21}\left(r_{\mathrm{p}}\right)$ \\
\hline T14V-J1 & 15 & $0 \cdot 6$ & $3 \cdot 5$ & $0 \cdot 6$ & $4 \cdot 0$ \\
\hline $\mathrm{T} 14 \mathrm{~V}_{-} \mathrm{J} 1$ & 50 & 0.7 & 3.5 & $0 \cdot 7$ & $2 \cdot 5$ \\
\hline T14V-J1 & 250 & 0.5 & $3 \cdot 5$ & $0 \cdot 8$ & $1 \cdot 3$ \\
\hline 5951 & 15 & $0 \cdot 5$ & $3 \cdot 8$ & $0 \cdot 6$ & $3 \cdot 5$ \\
\hline 5951 & 50 & $0 \cdot 6$ & $5 \cdot 5$ & $0 \cdot 7$ & $3 \cdot 5$ \\
\hline 5951 & 250 & $0 \cdot 6$ & $3 \cdot 5$ & 0.7 & $3 \cdot 0$ \\
\hline
\end{tabular}


surfaces, bearing the lectin responsible for the co-adhesion interaction, to a hydrophobic surface. Consequently, the results of this paper support the notion that interspecies binding between microbial pairs is at least partly mediated by electrostatic and acid-base interactions, in addition to the ever-present attractive Lifshitz-van der Waals' forces.

\section{ACKNOWLEDGEMENTS}

We are greatly indebted to Mrs Marjon Schakenraad-Dolfing for manuscript preparation and to $\mathrm{Mr}$ Joop de Vries for performing the streaming potential measurements.

\section{REFERENCES}

Absolom, D. R., Lamberti, F. V., Policova, Z., Zingg, W., Van Oss, C. J. \& Neumann, A.W. (1983). Surface thermodynamics of bacterial adhesion. Appl Environ Microbiol 46, 90-97.

Bos, R., Van der Mei, H. C., Meinders, J. M. \& Busscher, H. J. (1994). A quantitative method to study co-adhesion of microorganisms in a parallel plate flow chamber: basic principles of the analysis. J Microbiol Methods 20, 289-305.

Bos, R., Van der Mei, H. C. \& Busscher, H. J. (1995). A quantitative method to study co-adhesion of microorganisms in a parallel plate flow chamber: analysis of the kinetics of co-adhesion. $J$ Microbiol Methods 23, 169-182.

Bos, R., Van der Mei, H. C., De Vries, J. \& Busscher, H. J. (1996). The role of physico-chemical and structural surface properties in co-adhesion of microbial pairs in a parallel plate flow chamber. Colloids Surf B: Bininterfaces (in press).

Busscher, H. J., Weerkamp, A. H., Van der Mei, H. C., Van Pelt, A. W. J., De Jong، H. P. \& Arends, J. (1984). Measurement of the surface free energy of bacterial cell surfaces and its relevance for adhesion. Appl Eniron Microbiol 48, 980-983.

Busscher, H. J., Cowan, M. M. \& Van der Mei, H. C. (1992). On the relative importance of specific and non-specific approaches to oral microbial adhesion. FEMS Microbiol Rev 88, 199-210.

Cisar, J. O. \& Vatter, A. E. (1979). Surface fibrils (fimbriae) of Actinomyces viscosus T14V. Infect Immun 24, 523-531.

Cisar, J. O., Vatter، A. E., Clark, W. B., Curl, S. H., Hurst-Calderone, S. \& Sandberg, A. L. (1988). Mutants of Actinomyces viscosus T14V lacking type 1, type 2, or both types of fimbriae. Infect Immun 56, 2984-2989.

Elimelech, M. (1990). Indirect evidence for hydratation forces in the deposition of polystyrene latex colloids on glass surfaces. $J$ Cbem Soc Faraday Trans 86, 1623-1624.

Ellen, R. P., Veisman, H., Buivids, I. A. \& Rosenberg, M. (1994). Kinetics of lactose-reversible coadhesion of Actinomyces naeslundi WVL 398A and Streptococcus oralis 34 on the surface of hexadecane droplets. Oral Microbiol Immunol 9, 364371.

Gibbons, R. J. \& Nygaard, M. (1970). Interbacterial aggregation of plaque bacteria. Arch Oral Biol 15, $1397-1400$.

Handley, P. S., Hesketh, L. M. \& Moumena, R. A. (1991). Charged and hydrophobic groups are localized in the short and long tuft fibrils on Streptococous sanguis strains. Biofouling 4, 105-111.
Hiemenz, A. M. (1977). Electrophoresis and other electrokinetic phenomena. In Principles of Colloid and Surface Clbemistry, pp. 452-487. Edited by J. J. Lagowski. New York \& Basel: Marcel Dekker.

Kolenbrander, P. E. (1989). Surface recognition among oral bacteria: multi-generic coaggregations and their mediators. Crit Rev Microbiol 17, 137-155.

Mclntire, F. C., Vatter, A. E., Baros, J. \& Arnold, J. (1979). Mechanisms of coaggtegation between Actinomyces viscosus T14V and Streptococcus sanguits 34. Infect Immun 21, 978-988.

Pashley, R. M. \& Israelachvili, J. N. (1984). DI,VO and hydratation forces between mica surfaces in $\mathrm{Mg}^{2+}, \mathrm{Ca}^{2+}, \mathrm{Sr}^{2+}$ and $\mathrm{Ba}^{2+}$ chloride solutions. I Colloid Interface Sci 97, 446-455.

Pratt-Terpstra, I. H., Weerkamp, A. H. \& Busscher, H. J. (1989). The effect of pellicle formation on streptococcal adhesion to human enamel and artificial substrata with various surface free energies. J Dent Res 68, 463-467.

Quiocho, F. A. (1986). Carbohydrate-binding proteins: tertiary structures and protein-sugar interactions. Annu Rev Biocbem 55, 287-315.

Rosenberg, E. (1986). Microbial surfactants. CRC Crit Rev Biotecbnol 3, 109-131.

Ruardy, T. G., Schakenraad, J. M., Van der Mei, H. C. \& Busscher, H. J. (1995). Adhesion and spreading of human skin fibroblasts on physicochemically characterized gradient surfaces. J Biomed Mater Res 29, 1415-1423.

Rutter, P. R. \& Vincent, B. (1980). The adhesion of microorganisms to surfaces: physico-chemical aspects. In Microbial Adhesion to Surfaces, pp. 79-93. Edited by R. C. W. Berkeley, J. M. Lynch, J. Melling, P. R. Rutter \& B. Vincent. Chichester: Ellis Horwood.

Sjollema, J. \& Busscher, H. J. (1990). Deposition of polystyrene particles in a parallel plate flow cell. 2. Pair distribution functions between deposited particles. Colloids Surf 47, 337-354.

Sjollema, J., Busscher, H. J. \& Weerkamp, A. H. (1988). Deposition of oral streptococci and polystyrene latices onto glass in a parallel plate flow cell. Biofouling 1, 101-112.

Sjollema, J., Busscher, H. J. \& Weerkamp, A. H. (1989). Real-time image analyses of adhering microorganisms in a parallel plate flow cell using automated image analysis. J Mirrobiol Methods 9, 73 78.

Van Loosdrecht, M. C. M. \& Zehnder, A. J. B. (1990). Energetics of bacterial adhesion. Experientia 46, 817-821.

Van Oss, C. J. (1995). Hydrophobicity of biosurfaces - origin, quantitative determination and interaction energies. Colloids Surf B: Biointerfaces 5, 91-110.

Van Oss, C. J., Good, R. J. \& Chaudhury, M. K. (1986). The role of van der Waals forces and hydrogen bonds in "hydrophobic interactions" between biopolymers and low energy surfaces. J Colloid Interface Sci 111, 378-390.

Van Wagenen, R. J. \& Andrade, J. D. (1980). Flat plate streaming potential investigations: hydrodynamics and electrokinetic equivalency. J Colloid Interface $S_{c i}$ 76, 305-314.

Verrier, D., Mortier, B. \& Albagnac, G. (1987). Initial adhesion of methanogenic bacteria to polymers. Biotecbnol Lett 9, 735-740.

Received 19 February 1996; revised 29 April 1996; accepted 3 May 1996. 